\title{
An Analytical Approach For Transmission Expansion Planning with Generation Variations
}

\author{
Maneesh Kumar \\ Indian Institute of Technology, Roorkee, India
}

\begin{abstract}
Today, the transmission expansion planning for an existing power system under different constraints, is one of the major challenge for power engineers. There are several reasons; one of the reasons is rapid growth in load and inadequate capacity addition. Hence, it is important and essential to implement an algorithm for the transmission expansion which works well and have a good feasibility under certain assumptions and available constraints. Transmission expansion planning used in proposed paper works on an analytical algorithm which has been implemented for specific load condition with variations in generation. For that purpose, an economical factor has been measured that considers economical aspects of the line to be added for expansion. The prescribed analytical approach is also implemented for its feasibility check on a practical case study system.
\end{abstract}

Index Terms-Central electricity authority (CEA), Distributed generation(DG), Economic index (Ei), Power system operator (PSO), Power world simulator (PWS), Renewable energy sources (RES), Transmission expansion planning (TEP).

\section{INTRODUCTION}

Any power system can only work reliably, when there exists some favorable system condition and constraints for which it is designed to work upon. With increase in complexities, planning for a suitable and reliable transmission system becomes very difficult for a power engineer. Hence, there must always be a coordination between three entities i.e. generation, transmission and distribution for enhancement of overall system stability. While working upon transmission expansion planning the main consideration emphasis on the system stability and reliability.

In many developing countries the majority of power system planning comes from inefficient capacity utilization, very high line losses, unpredictable growth in electricity demand that exceeds the available capacity addition [1]. Hence, optimal solutions are needed to overcome from these problems. This will include a suitable scheduling and operation of existing capacities and detecting the bottlenecks in generation, transmission, etc. In this paper the emphasis is on an optimal solution for the transmission expansion under existing load conditions to reduce expenditures for new transmission corridors [2]. The methodology used here is based on MWmile method under a deregulated power system environment which considered line length as well as cost associated with the line being added. The methodology is simple to implement also, convergence rate for the applied approach is fast compare to other similar approaches for transmission expansion planning. In TEP, we try to implement cost effective approaches and other measures like series compensation, re-

\author{
Raminder Kaur \\ P.E.C University of Technology, Chandigarh, India
}

conductoring, addition of one or more lines in the existing system and also alteration of the transmission voltage level. The responsibility of power system operators (PSO) such as utilities, is to provide suitable expansion to transmission corridor so that power transfer with in the corridor become more reliable and system stability should increase [4,11]. There is a unique effect of restructuring and deregulation of the power industry on the objectives of TEP. Therefore, there have been an increased the uncertainties in the system and also the idea behind TEP greatly influenced [5]. Due to these changes, new approaches and criteria are desirable for TEP. The expansion approach used in this paper has uniqueness in terms of its easy applicability and fast convergence unlike some other methods; also the solutions coming after iteration are more practical as seen from the case study.

\section{TRANSMISSION EXPANSION PLANNING WITH RESPECT TO GENERATION CHANGE}

\section{A. Assuming a $60 \%$ toad increment in overall network}

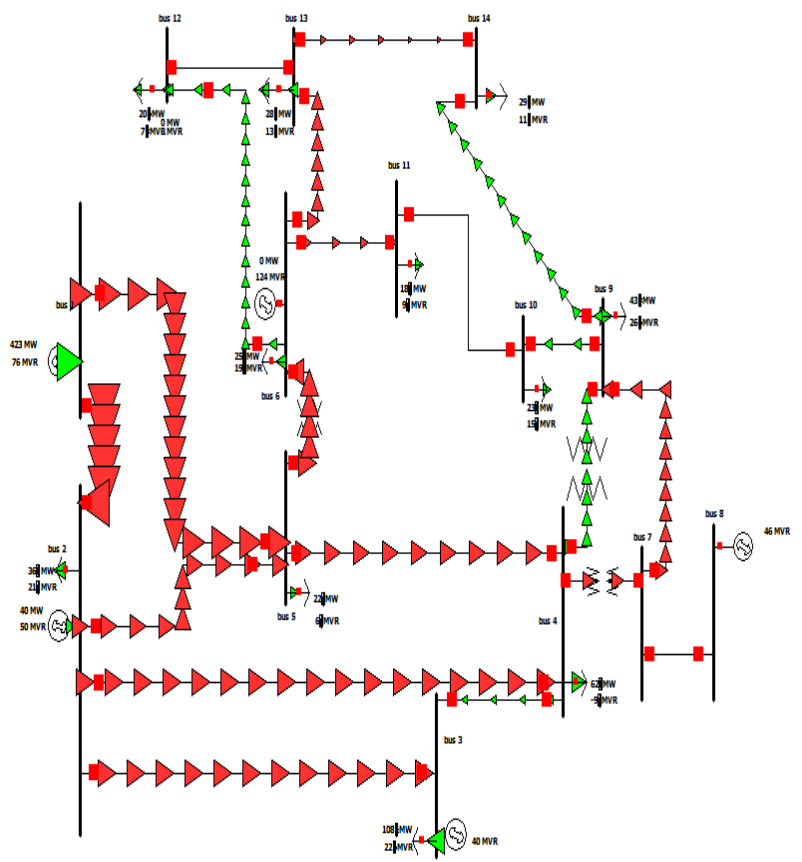

Fig1. IEEE 14 bus system with $60 \%$ uniform load increment on PWS

Here, the red arrows show the overloading in the system and hence, to overcome from this we have to add new alternate lines in the network. The system data after simulating the system on PWS with a $60 \%$ load increment is given in C. below. A60\% load increment is based on 5-7 years planning 
criteria of CEA $[3,9,10]$. Complete simulation has been done using PWS and MATLAB. Fig. 1 shows the IEEE 14 bus system which is overloaded under given load conditions. $E_{i}$ is obtained for each case using MATLAB through a program.

\section{B. Assuming a solar plant of $75 \mathrm{MW}$ capacity at bus no. 10}

We have considered a solar plant with a capacity of $75 \mathrm{MW}$ connected at bus 10 . While working on PWS we assumed constant atmospheric conditions i.e. the output of the sources is constant to $75 \mathrm{MW}$ irrespective to the changes in weather conditions.

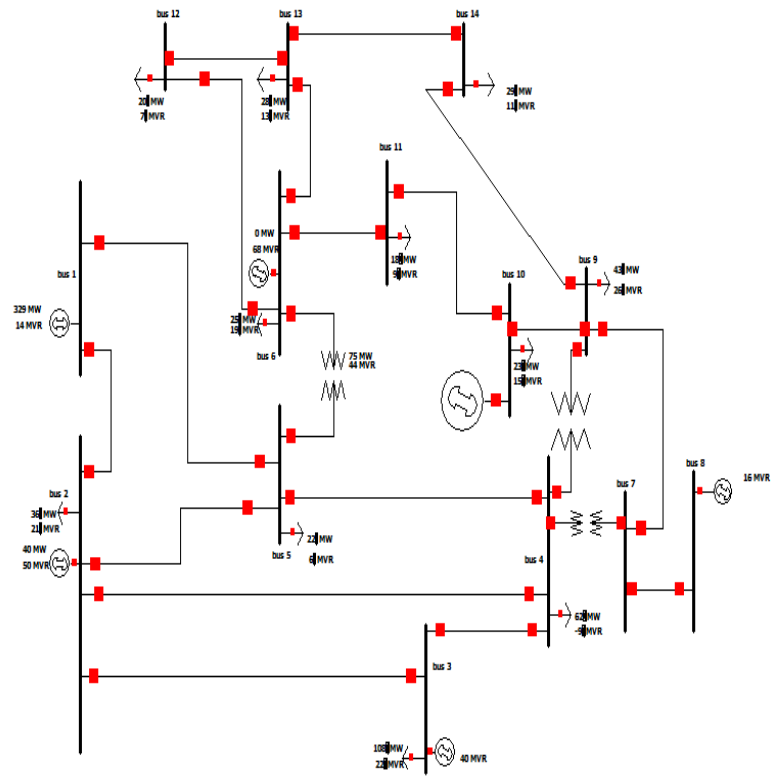

Fig 2. Distributed source added at bus no. 10

With already $60 \%$ load increment now we add a distributed source (solar farm with capacity of $75 \mathrm{MW}$ ) at bus 10 and check the loading of the network.Fig.2 shows a capacity addition at bus 10 as per availability.

Below is the system data in case of $60 \%$ load increment and new generation at bus 10 . Here red color digits show the overloading in the network. From the system data it is observed that there are many lines in system under consideration are overloaded and hence, there is a need to remove overloading within the system.

The algorithm used here are being applied on the transmission lines only that means calculation of total number of alternate lines added or removed are only transmission lines of the system and not the transformers.

The simulation results show the different columns like bus numbers between which the lines are connected, number of circuits, status of the circuit i.e. whether they are either closed or open, connected transformers between bus no. 4-7, 4-9 and 5-6, the MW flow, MVAr flow, MVA flow also MVA limit between different line are also obtained from the simulation.

Losses occurred from power flow between different lines can also be observed from the simulation. The alternate lines needed for expansion are calculated in table 1 and will be described in later paragraphs.

C. Simulation results with $60 \%$ load increment and distributed source at bus 10

\begin{tabular}{|c|c|c|c|c|c|c|c|c|c|c|c|c|c|c|}
\hline & from lumber & of from llame & Tollumber & Tollame & Grouit & Status & Xfmr & from 1 WII & from Mvar & from HNA & Lim MVA & Hax Percent | & MWl Loss & Hvar loss \\
\hline 1 & 1 & bus 1 & 2 & bus2 & 2 & Closed & 110 & 2233 & .13 & 2233 & 12000 & 186.1 & 9.66 & 2441 \\
\hline 2 & 1 & bus 1 & 5 & bus 5 & 3 & Closed & 110 & 105.9 & 15.5 & 107.0 & 65.0 & 164.6 & 6.23 & 21.14 \\
\hline 3 & 2 & bus? & 3 & bus 3 & 4 & Closed & 110 & 88.7 & 27 & 88.8 & 36.0 & 246.6 & 3.98 & 1285 \\
\hline 4 & 2 & bus? & 4 & bus 4 & 2 & Closed & 110 & 71.8 & $\cdot 14$ & 718 & 65.0 & 110.5 & 3.22 & 6.40 \\
\hline 5 & 2 & bus2 & 5 & bus 5 & 1 & Closed & 110 & 57.1 & 18 & 57.2 & 50.0 & 114.3 & 200 & 3.06 \\
\hline 6 & 3 & bus3 3 & 4 & bus 4 & 1 & Closed & 110 & .233 & 79 & 24.6 & 65.0 & 39.4 & 0.49 & -1.75 \\
\hline 7 & 4 & bus 4 & 5 & bus 5 & 4 & Closed & 110 & .60 .6 & 19.2 & 63.6 & 45.0 & 1420 & 0.63 & 0.87 \\
\hline 8 & 4 & bus 4 & 1 & bus7 & 1 & Closed & Yes & 27.6 & 8.4 & 28.9 & 55.0 & 53.6 & 0.00 & 192 \\
\hline 9 & 4 & bus 4 & 9 & bus9 & 1 & Closed & Yes & 15.8 & .0 .3 & 15.8 & 320 & 49.7 & 0.00 & 1.51 \\
\hline 10 & 5 & bus 5 & 6 & bus 6 & 2 & Closed & Yes & 71.6 & 6.0 & 718 & 45.0 & 159.8 & 0.00 & 13.04 \\
\hline 11 & 6 & bus 6 & 11 & bus 11 & 2 & Closed & 110 & .53 & 11.2 & 124 & 18.0 & 68.9 & 0.15 & 0.31 \\
\hline 12 & 6 & bus6 6 & 12 & bus 12 & 1 & Closed & 110 & 19.1 & 10.1 & 21.6 & 320 & 67.4 & 0.57 & 1.19 \\
\hline 13 & 6 & bus 6 & 13 & bus 13 & 3 & Closed & 110 & 328 & 21.3 & 39.1 & 320 & 1223 & 1.01 & 199 \\
\hline 14 & 1 & bus? & 8 & bus 8 & 1 & Chosed & 110 & 0.0 & .15 .6 & 15.6 & 320 & 50.2 & 0.000 & 0.45 \\
\hline 15 & 1 & bus? & 9 & bus 9 & 2 & Closed & 110 & 27.6 & 53 & 28.1 & 320 & 87.9 & 0.00 & 0.92 \\
\hline 16 & 10 & bus 10 & 9 & bus 9 & 2 & Closed & 110 & 28.1 & 29.6 & 40.8 & 320 & 127.4 & 0.53 & 140 \\
\hline 17 & 9 & bus9 & 14 & bus 14 & 1 & Closed & 110 & 27.9 & 54 & 28.5 & 320 & 89.0 & 1.10 & 235 \\
\hline 18 & 11 & bus 11 & 10 & bus 10 & 3 & Closed & 110 & 23.5 & 1.9 & 23.5 & 120 & 199.6 & 0.47 & 1.10 \\
\hline 19 & 12 & bus 12 & 13 & bus 13 & 2 & Closed & 110 & $\cdot 1.5$ & 1.9 & 24 & 120 & 20.3 & 0.01 & 0.01 \\
\hline 20 & 13 & bus 13 & 14 & bus 14 & 5 & Closed & 110 & 23 & 82 & 8.5 & 120 & 70.8 & 0.14 & 0.28 \\
\hline
\end{tabular}

TABLE 1. ADDITIONAL LINES NEEDED WITH 60\% LOAD INCREMENT AND DISTRIBUTION GENERATION AT BUS 10.

\begin{tabular}{|l|l|l|l|l|}
\hline $\begin{array}{c}\text { From } \\
\text { bus }\end{array}$ & $\begin{array}{c}\text { To } \\
\text { bus }\end{array}$ & \% loading & $\begin{array}{c}\text { Total } \\
\text { lines }\end{array}$ & Alternate lines \\
\hline 1 & 2 & 186.1 & 3 & $3-1=2$ \\
\hline 1 & 5 & 164.6 & 3 & $3-1=2$ \\
\hline 2 & 3 & 246.6 & 4 & $4-1=3$ \\
\hline 2 & 4 & 110.5 & 2 & $2-1=1$ \\
\hline 2 & 5 & 114.3 & 2 & $2-1=1$ \\
\hline 4 & 5 & 142 & 2 & $2-1=1$ \\
\hline 5 & 6 & 159.8 & 2 & $3-1=1$ (Transformer) \\
\hline 6 & 13 & 122.3 & 2 & $2-1=1$ \\
\hline 9 & 10 & 127.4 & 2 & $2-1=1$ \\
\hline 10 & 11 & 199.6 & 3 & $3-1=2$ \\
\hline
\end{tabular}

Table 1 shows the number of alternate lines added in the system based on the criteria mentioned below. Here, $80 \%$ loading is considered while adding alternate line into the system. $20 \%$ margin is taken for line safety and simplicity [3]. Therefore, each line is having a maximum loading of $80 \%$, if it is more than that existing percentage loading divided by $80 \%$ loading gives the new alternate lines. Fig. 3 is obtained after adding alternating lines based on $80 \%$ loading condition as mentioned above. Approaches used for TEP should also consider different uncertainties present in the system either from load side or from generation side i.e. future generation location, 
intermittency of RES production, costs of fuel, growth in load etc.) [6-7]

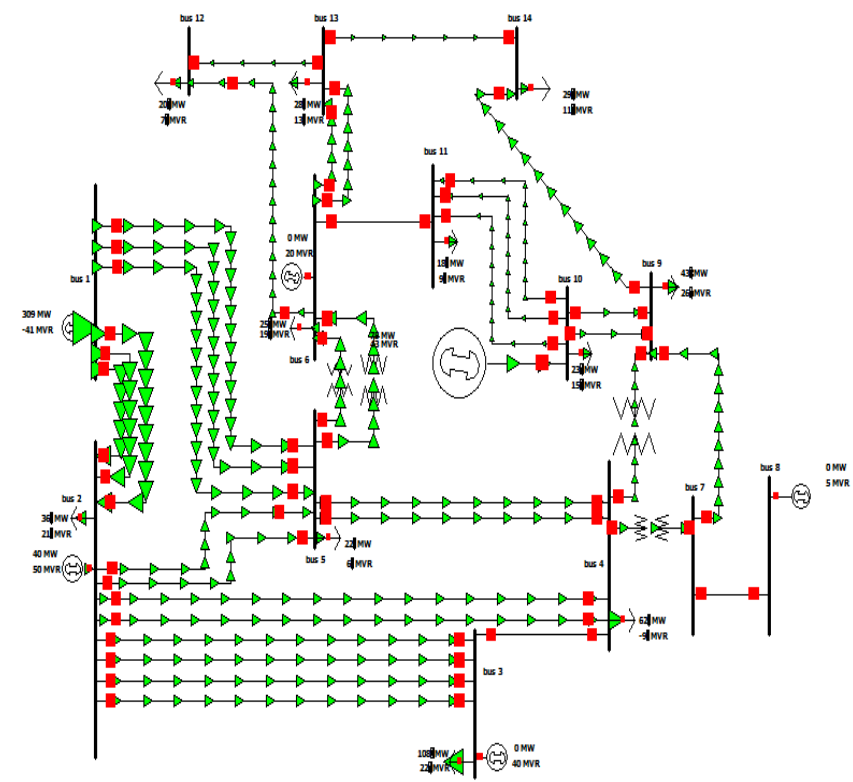

Fig3. Network with new alternate lines

\section{OPTIMIZATION OF THE ABOVE NETWORK USING OPTIMAL ALGORITHM}

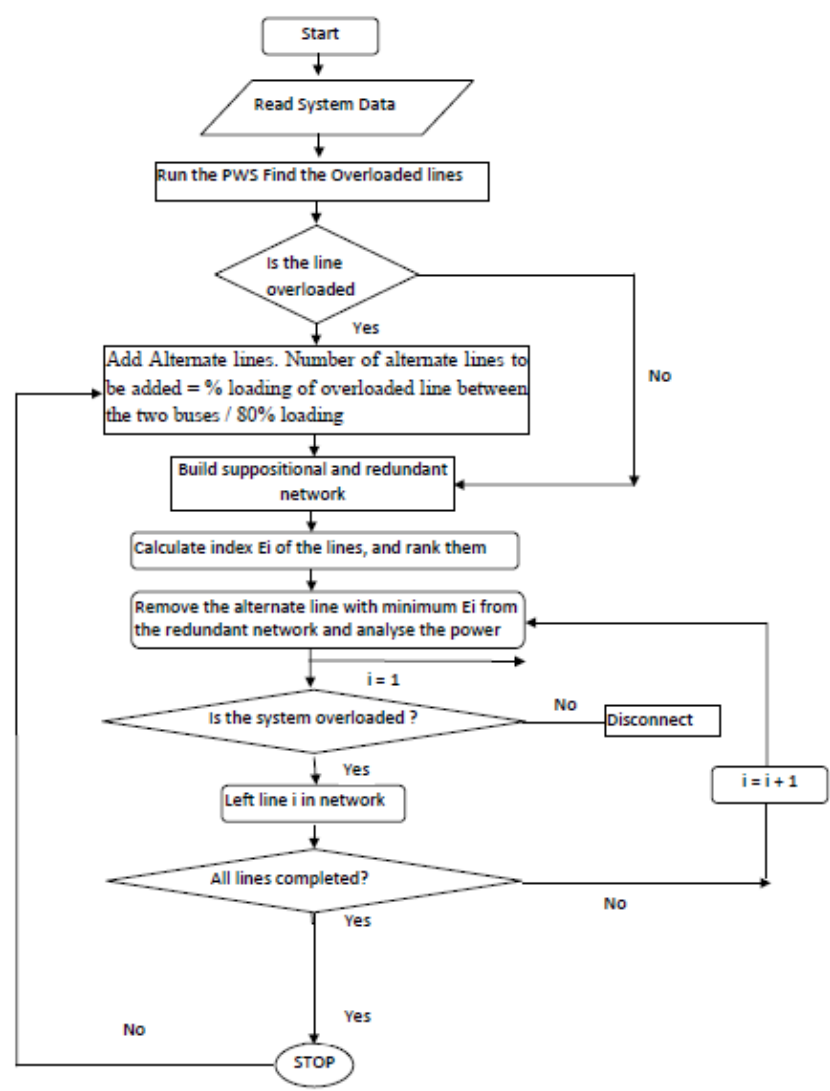

Fig.3.1 shows the algorithm used to obtain the optimization model of the network under consideration using economical factor known as economic index (Ei) described in coming section A, below. There are certain steps used under applied analytical algorithm and are described as follows:

Step 1: Run the Power world simulator to check that no route is overloaded in the network system data.

Step 2: Add another alternate line on this route in case any route is overloaded keeping the line loading limit to $80 \%$ of its capacity.

Step 3: Number of alternate lines to be added $=\%$ loading of overloaded line between the two buses divided by $80 \%$ loading.

Step 4: Build the suppositional/ redundant network by adding all the alternate lines.

Step 5: Calculate the economic index of all the transmission lines.

Step 6: Tabulate the alternate lines in the increasing order of their economic index.

Step 7: Remove the alternate line with minimum economic index from the redundant network.

Step 8: Reconnect the line which was removed in Step 5 if there is overloading in any line in the network.

Step 9: Remove the alternate line with next higher minimum economic index in the order.

Step 10: Continue the removal of alternate lines with minimum economic index fulfilling our criteria for no overloading of any line met in the process.

Step 11: Repeat the algorithm until removal of all the added alternate lines has been tested. At last we will be left with the alternate lines which reduce the percentage overloading of overloaded lines and maximizes the objective function i.e. the overall increase in the economic efficiency of system expressed as a ratio of sigma of economic index of all transmission lines and the total number of lines in the system at each step of removal of alternate line in the transmission network expansion planning algorithm. The analytical algorithm used in paper for finding out the optimal solution, is basically a set of instruction or a set of some specific steps which are used to find out overall task of optimization.

\section{A. Economic Index (Ei)}

Economic efficient lines can be obtained from a novel introduced factor which is acknowledged as Economic index (Ei) and is defined as [2]:

$\mathbf{E}_{\mathrm{i}}=\mathbf{I}_{\mathrm{i}} / \mathbf{C}_{\mathrm{i}}=\left[\mathbf{E}\left(\mathbf{P}_{\mathrm{i}}\right)^{*} \mathbf{D}_{\mathrm{i}}^{*} \boldsymbol{*} \boldsymbol{\rho}\right] / \mathbf{C}_{\mathrm{i}}$

Where,

$\mathbf{I}_{\mathbf{i}}:$ profit prospect of alternative line $\mathbf{i}$

$\mathbf{C}_{\mathbf{i}}$ : Cost of alternative line $\mathbf{i}$

$\mathbf{P}_{\mathrm{i}}$ : Actual power flow

$\mathbf{D}_{\mathbf{i}}$ : Length of line i

$\boldsymbol{\rho}$ : Pre-determined unit cost factor of each transmission line

If $\mathbf{E}_{\mathbf{i}}>\mathbf{E}_{\mathbf{j}}$, this implies that the line $\mathbf{i}$ is more economically efficient than line $\mathbf{j}$.

Higher is the economic index more efficient will be the line.

Fig. 3.1 Flowchart for Analytic algorithm for TEP 


\section{Iteration 1. Without removal of any alternating line.}

Fig.4 below shows the chart for $\mathrm{E}_{\mathrm{i}}$ of network when there is no exclusion of any alternate line. Hence, summation of all $E_{i}$ divided by existing number of line gives the average $E_{i}$ of the network.

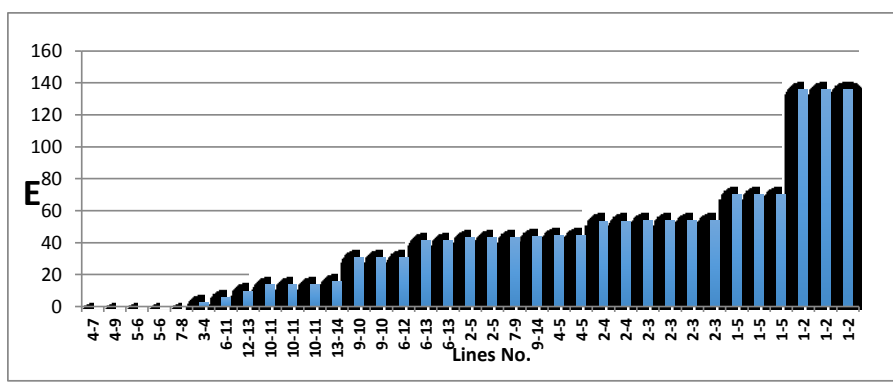

Fig4. Economic index with no exclusion of any alternate line

Average (Ei). for the existing number of lines is 1389.6/31=43.42

Above figure shows the lines with minimum and maximum $\left(E_{i}\right)$ in ascending order i.e. minimum and maximum efficient lines. Hence, the choice of removal of lines is based on this order. The least efficient line is preferred to remove first while maintaining system stability considerations i.e. $80 \%$ loading condition should also be maintained.

TABLE 2. ROUTE THAT CAN BE REMOVED FROM SYSTEM WHILE MAINTAING $80 \%$ LOADING CONDITION

\begin{tabular}{|r|r|c|}
\hline \multicolumn{1}{|c|}{ Route } & \multicolumn{1}{|c|}{ Ei } & Status \\
\hline $10-11$ & 14 & Not removed \\
\hline $9-10$ & 31 & Not removed \\
\hline $6-13$ & 41.6 & Not removed \\
\hline $2-5$ & 43.2 & Removed \\
\hline $4-5$ & 44.8 & Removed \\
\hline $2-4$ & 53.6 & Not removed \\
\hline $2-3$ & 54 & Removed \\
\hline $1-5$ & 70.4 & Not Removed \\
\hline $1-2$ & 135.8 & Not Removed \\
\hline
\end{tabular}

Table 2 shows the routes that can be excluded based on the $80 \%$ loading condition. It can be seen that route number $2-5$, 4-5 and 2-3 can be removed from the network for the stability and loading conditions along with obtained $E_{i}$.

Iteration 2. Exclusion of route 2-5 from the network

The average $E_{i}$ for existing number of lines from below figure after the exclusion of less efficient line $2-5$ will be= $1425.4 / 30=47.51$. Fig. 5 shows the chart for $E_{i}$ of network with exclusion of route $2-5$.

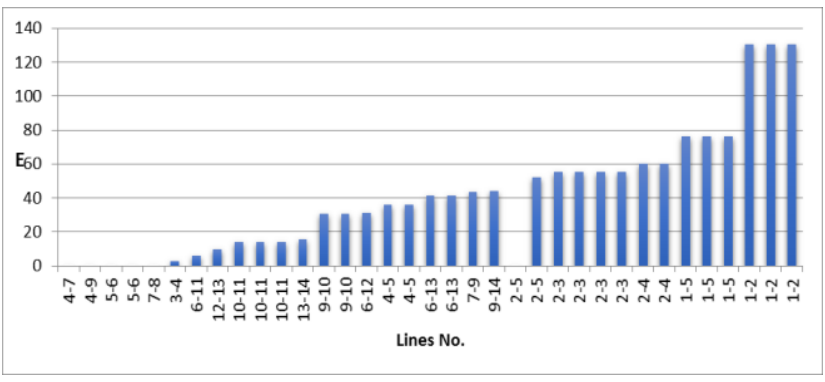

Fig5. Economic index after exclusion of less efficient line 2-5

\section{Iteration 3: Exclusion of route 4-5}

The average Ei of the system for existing number of lines from below figure after the exclusion of less efficient lines 2-5, 4-5 will be $=1419.4 / 29=48.94$. Fig. 6 shows the chart for $E_{i}$ of network with exclusion of route $4-5$ from the network.

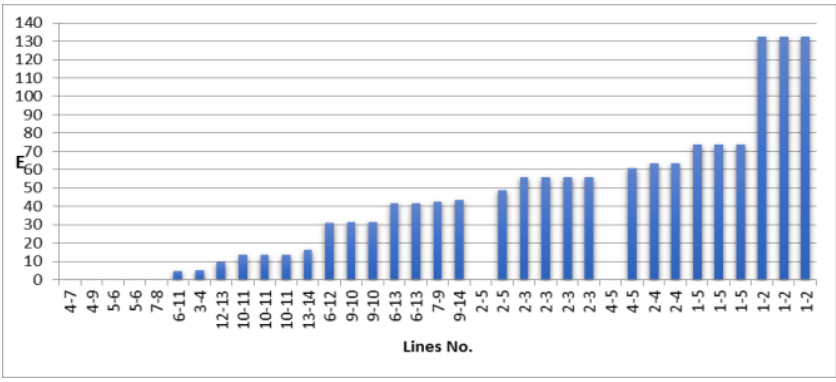

Fig6. Economic index after exclusion of inefficient line 4-5

\section{Iteration 4: Exclusion of route 2-3}

The average Ei of the system for existing number of lines from below figure after the exclusion of less efficient lines 2-5, 4-5 and $2-3$ will be $=1425.8 / 28=\mathbf{5 0 . 9 2}=\mathbf{4 9 . 1}$. Fig. 7 shows the chart for $E_{i}$ of network with exclusion of route 2-3 from the network.

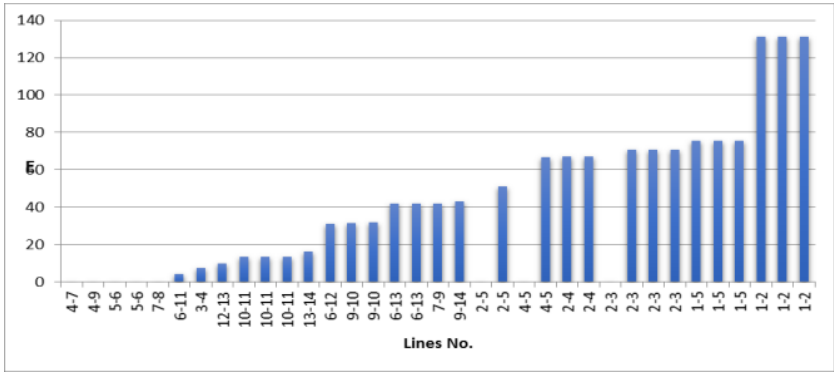

Fig7.Economic index after exclusion of less efficient line 2-3

\section{B. Nework data corresponding to optimal system}

- Total number of transmission lines (without any exclusion) $=31$

- $\quad$ Base network transmission lines $=17$

- Total transformers in the network $=4$

- Total alternate lines added to network=14 (excluding a transformer between bus 5-6) so that $(17+14=31=$ total transmission lines $)$

- Total alternate lines left in network=11(14-3 removed lines) 
- Total transmission lines left in network $=28(31-3$ removed lines)

Therefore, the optimization algorithm provides a new network that needs only 28 lines out of 31 which corresponds to the most economical and efficient network.

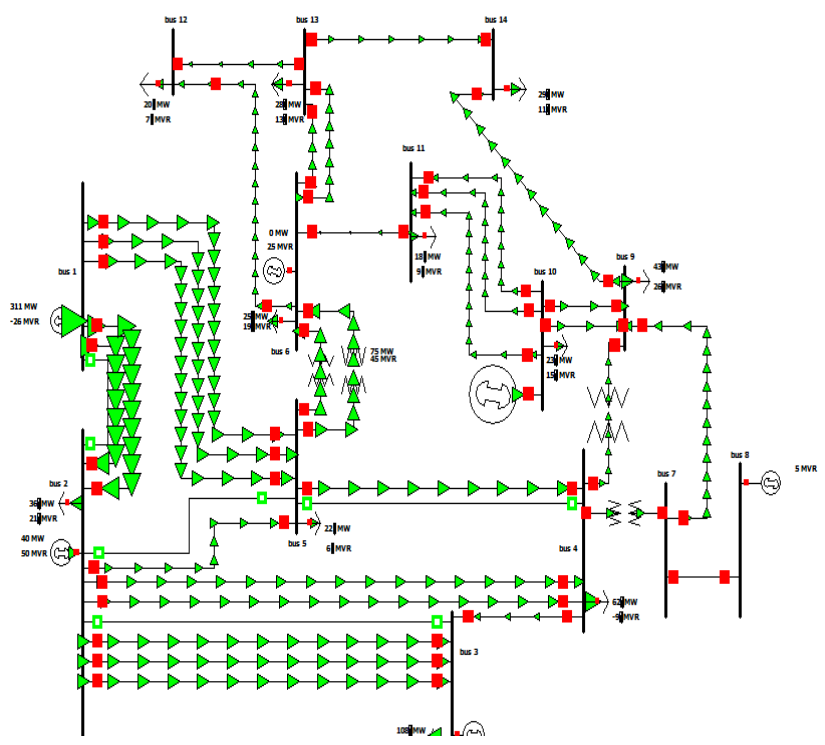

Fig8. New network after optimization

Fig.8 shows an optimized network that is obtained after applying analytical algorithm in the network. Table 3 below shows overall Ei pattern for all four iteration cases also table 4 shows overall economic index with all available routes.

TABLE 3. PATTERN FOR ECONOMIC INDEX (Ei)

\begin{tabular}{|c|c|c|c|c|}
\hline S.n. & $\begin{array}{c}\text { Line to } \\
\text { be } \\
\text { removed }\end{array}$ & $\operatorname{Ei(overall)}$ & $\begin{array}{c}\text { Lines in } \\
\text { network }\end{array}$ & $\begin{array}{c}\text { Ei per } \\
\text { line }\end{array}$ \\
\hline 1 & $\begin{array}{c}\text { No } \\
\text { Removal }\end{array}$ & 1389.6 & 31 & 43.42 \\
\hline 2 & $2-5$ & 1425.4 & 30 & 47.51 \\
\hline 3 & $4-5$ & 1419.4 & 29 & 48.94 \\
\hline 4 & $2-3$ & 1425.8 & 28 & 50.92 \\
\hline
\end{tabular}

TABLE 4. OVERALL ECONOMIC INDEX ( $\left.\mathrm{E}_{\mathrm{i}}\right)$ WITH ALL AVAILABLE ROUTES

\begin{tabular}{|r|r|r|}
\hline S.n. & Route & Ei (\%) \\
\hline 1 & $10-11$ & 14 \\
\hline 2 & $9-10$ & 31 \\
\hline 3 & $6-13$ & 41.6 \\
\hline 4 & $2-5$ & 43.2 \\
\hline 5 & $4-5$ & 44.8 \\
\hline 6 & $2-4$ & 53.6 \\
\hline 7 & $2-3$ & 54 \\
\hline 8 & $1-5$ & 70.4 \\
\hline 9 & $1-2$ & 135.8 \\
\hline
\end{tabular}

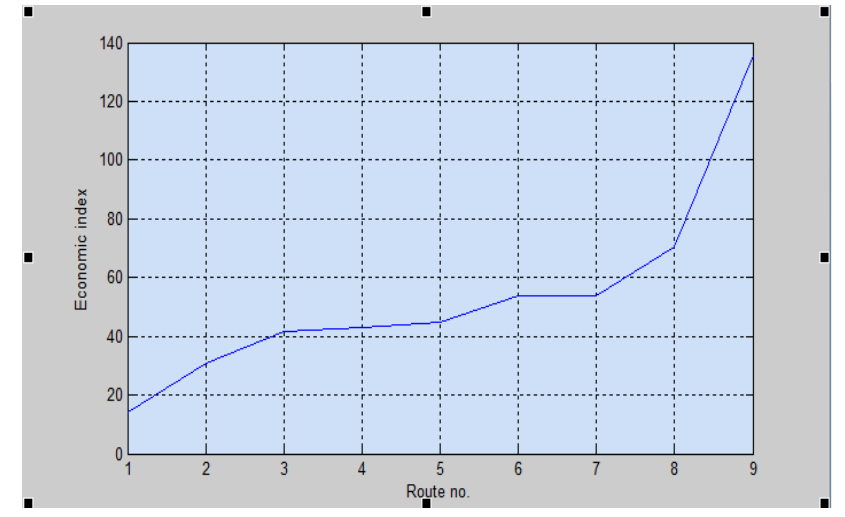

Fig 9. Graph between route and Economic index

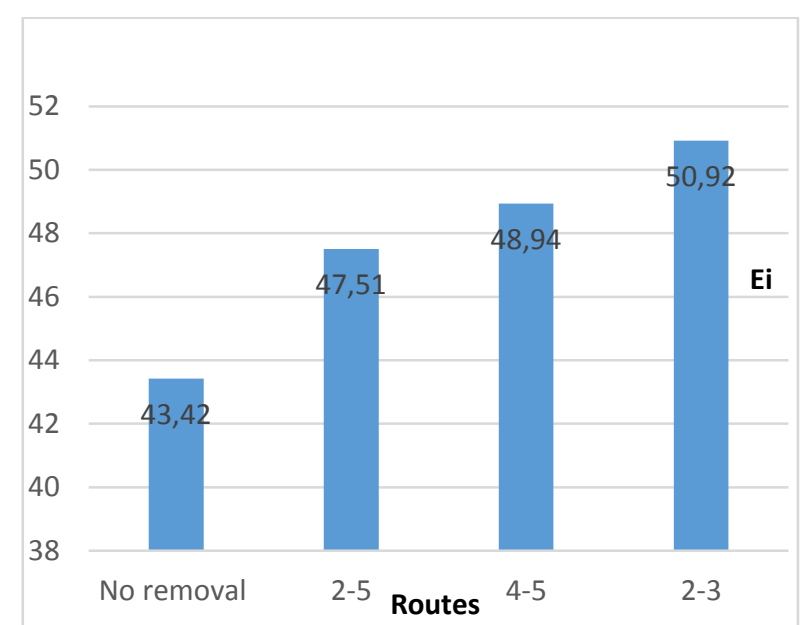

Fig10. Graph for average Economic index with removed line corresponding to $\mathrm{E}_{\mathrm{i}}$ order.

\section{CASE STUDY:}

A practical power system of Dehradun (In Uttarakhand, an Indian state) area has been considered here to implement analytical algorithm. The overall system data for the power system under consideration is given in table 5 in 2007. There are three load buses situated at three locations known as Majra, Purkul and Bindal as shown in fig.11. There are four generator buses placed at four different locations known as khodari, dhakrani, dhalipur, and kulhal one bus at rishikes considered as slack bus. Similarly, table 6 shows the system data of 2015.

TABLE 5. BUS DATA OF DEHRADUN SYSTEM IN 2007

\begin{tabular}{|c|c|c|}
\hline S. no. & Bus Name & Location \\
\hline 1. & Generator Bus & Khodari (60MW) \\
\hline & & Dhakrani(12MW) \\
\hline & & Dhalipur(16MW) \\
\hline & Slack Bus & Rishikesh(70MW) \\
\hline 3. & Load Bus & Majra (80MW) \\
\hline & & Purkul (35MW) \\
\hline & & Bindal(50MW) \\
\hline
\end{tabular}


Table 6. BUS DATA OF DEHRADUN SYSTEM IN 2015

\begin{tabular}{|c|c|c|}
\hline S. no. & Bus Name & Location \\
\hline 1. & Generator Bus & Khodari (60MW) \\
\hline & & Dhakrani(12MW) \\
\hline & & Dhalipur(16MW) \\
\hline & & Kulhal(12MW) \\
\hline 2. & Slack Bus & Rishikesh(70MW) \\
\hline 3. & Load Bus & Majra (96MW) \\
\hline & & Purkul (69MW) \\
\hline & & Bindal(81MW) \\
\hline
\end{tabular}

Iteration 1a: The power system network data of 2007 and 2015 are taken with corresponding increase in load in the duration from 2007-2015 as shown in fig.11. The below network is obtained after first iteration with an increment in load between 2007 to 2015 . The line length data and type of conductor used are obtained from the manual and power map available at Power Transmission Corporation of Uttarakhand state website [12]. It is observed from table 6 that in 2015, the load has increased on all the three load buses in the areas of Majra from $80 \mathrm{MW}$ to $96 \mathrm{MW}$, Purukul from $35 \mathrm{MW}$ to 69 MW and Bindal from $50 \mathrm{MW}$ to $81 \mathrm{MW}$.

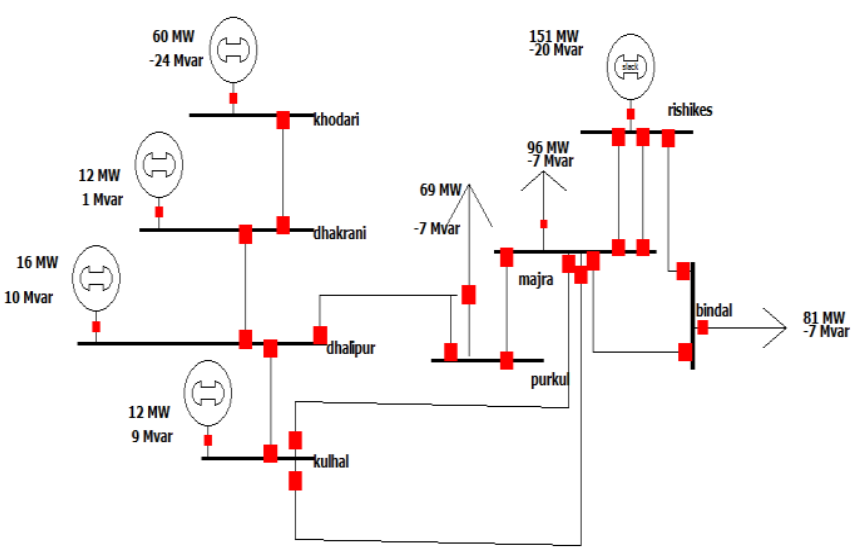

Fig.11 Dehradun area power system on PWS (with 2007-2015 load change)

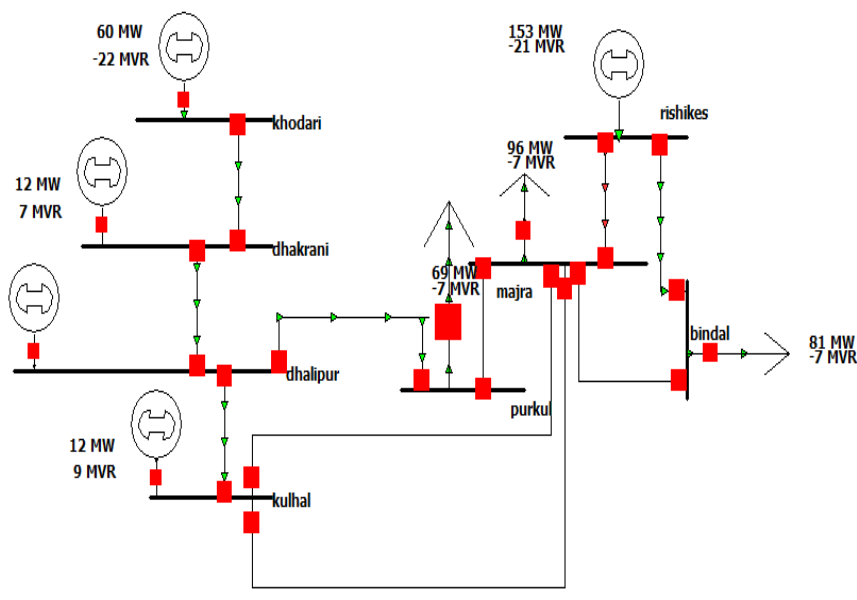

Fig.12 Overloaded system after first iteration
From fig. 12 is observed that there is overloading in the bus between Majra and Rishikesh. The algorithm when applied to the network along with the loading condition of the lines shows one more line is required in the areas between Majra and Rishikesh.

TABLE.7 ADDITIONAL LINES REQUIRED AFTER LOAD INCREMENT

\begin{tabular}{|l|l|l|l|l|}
\hline From bus & To bus & \% loading & Total lines & $\begin{array}{l}\text { Alternate } \\
\text { lines }\end{array}$ \\
\hline Rishikesh & Majra & 159 & 2 & $2-1=1$ \\
\hline
\end{tabular}

From table 7 it is observed that there is only one additional line is needed between Rishikesh and Majra for removing the system overloading and hence to obtain optimized network as there is no scope to remove any additional line from the system from the view point to system loading corresponding to $80 \%$ as considered throughout the system. Hence, system in fig. 13 below, is the optimized system which is also the actual or practical system present in Dehradun. fig.13 shows the optimal network.

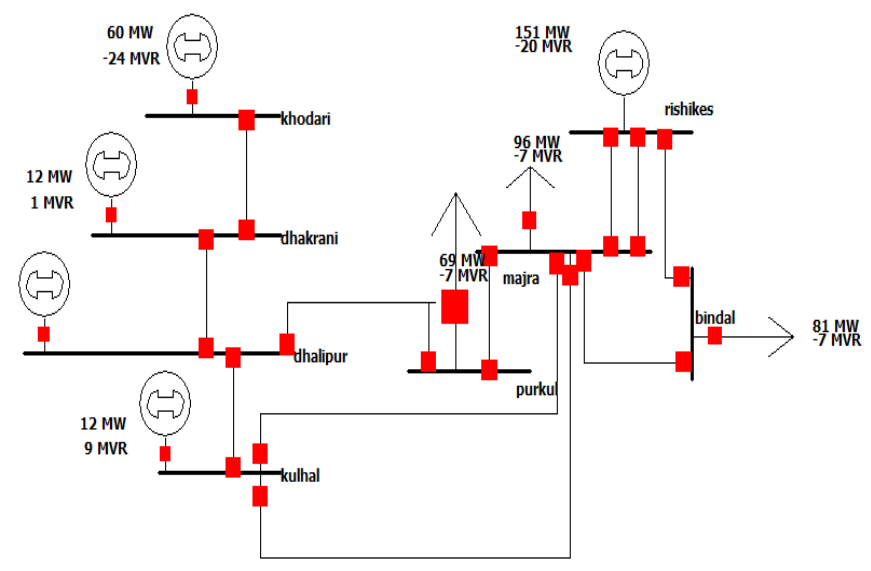

Fig.13 Optimized power system of Dehradun (2015) after addition of only one line

TABLE. 8 Ei OF THE SYSTEM WITH NO RES

\begin{tabular}{|c|l|c|}
\hline From Bus & To Bus & Ei \\
\hline 5.0 & 6.0 & 50.8 \\
\hline 4.0 & 6.0 & 52.4 \\
\hline 4.0 & 6.0 & 55.4 \\
\hline 6.0 & 8.0 & 74.6 \\
\hline 6.0 & 7.0 & 81.2 \\
\hline 6.0 & 7.0 & 81.2 \\
\hline 3.0 & 4.0 & 85.4 \\
\hline 3.0 & 5.0 & 89.2 \\
\hline 7.0 & 8.0 & 97.6 \\
\hline 1.0 & 2.0 & 120.0 \\
\hline 2.0 & 3.0 & 143.4 \\
\hline
\end{tabular}

Table. 8 shows the Ei of the Dehradun system when there is no RES in system. Bus numbering is obtained as per table 9. Table also gives require data like MW flow etc.

From the above table average $\mathrm{Ei}=931.2305 / 11=\mathbf{8 4 . 6 8 5}$. 
TABLE. 9 SYSTEM DATA OBTAINED FROM PWS AFTER FIRST ITERATION

\begin{tabular}{|c|c|c|c|c|c|c|c|c|c|c|c|c|c|c|}
\hline & From Name & To Number & To Name & Circuit & Status & \begin{tabular}{|l|} 
Branch \\
Device Type
\end{tabular} & Xfrmr & MW From & Mvar From & MVA From & Lim MVA & $\begin{array}{l}\% \text { of MVA } \\
\text { Limit (Max) }\end{array}$ & MW Loss & Mvar Loss \\
\hline 1 & khodari & & 2 dhakrani & 1 & Closed & Line & NO & 60.0 & $-24,0$ & 64.6 & 100,0 & 64.6 & 0.34 & 0.37 \\
\hline 2 & dhakrani & & 3 dhalipur & 1 & Closed & Line & NO & 71.7 & -23.4 & 75.4 & 100.0 & 75.4 & 0.30 & 0.41 \\
\hline 3 & dhalipur & & 4 kulhal & 1 & Closed & Line & NO & 42.6 & -10.3 & 43.9 & 100.0 & 43.9 & 0.10 & -0.05 \\
\hline 4 & dhalipur & & 5 purkul & 1 & Closed & Line & NO & 44.7 & -3.5 & 44,9 & 100.0 & 44.9 & 0.83 & -0.25 \\
\hline 5 & majra & & 4 kulhal & 1 & Closed & Line & NO & -27.8 & -0.8 & 27.8 & 100.0 & 28.1 & 0.31 & -1.37 \\
\hline 6 & majra & & 4 kulhal & 2 & Closed & Line & NO & -26.2 & -0.8 & 26.2 & 100.0 & 26.5 & 0.29 & -1.54 \\
\hline 7 & majra & & 5 purkul & 1 & Closed & Line & NO & 25.2 & -4.6 & 25.6 & 100.0 & 25.6 & 0.14 & -0.79 \\
\hline 8 & rishikes & & 6 majra & 3 & Closed & Line & NO & 49.8 & -6.7 & 50.2 & 50.0 & 100.4 & 0.96 & 0.21 \\
\hline 9 & rishikes & & 6 majra & 4 & Closed & Line & NO & 49.8 & -6.7 & 50.2 & 50.0 & 100.4 & 0.96 & 0.21 \\
\hline 10 & majra & & 8 bindal & 1 & Closed & Line & NO & 30.3 & -0.6 & 30.3 & 100.0 & 30.3 & 0.07 & -0.25 \\
\hline 11 & rishikes & & 8 bindal & 2 & Closed & Line & NO & 51.9 & -6.2 & 52.3 & 100.0 & 52.3 & 1.13[ & 0.45 \\
\hline
\end{tabular}

Iteration 1b: Considering one RES of $25 \mathrm{MW}$ capacity at heavily loaded bus of Majara. The consideration behind capacity addition is as per " $24 \times 7$ power for all Uttarakhand" a joint initiative by Government of India and Government of Uttarakhand, manual. There is a proposal of a capacity addition of renewable energy sources into existing system. The addition of solar power (grid connected as well as off grid) for the year 2016-17, has an average of approximately 24 MW (32.1 MW for 2016; 15.4 MW for 2017) [9-10]. So, a solar capacity addition of $25 \mathrm{MW}$ is taken in our case study.

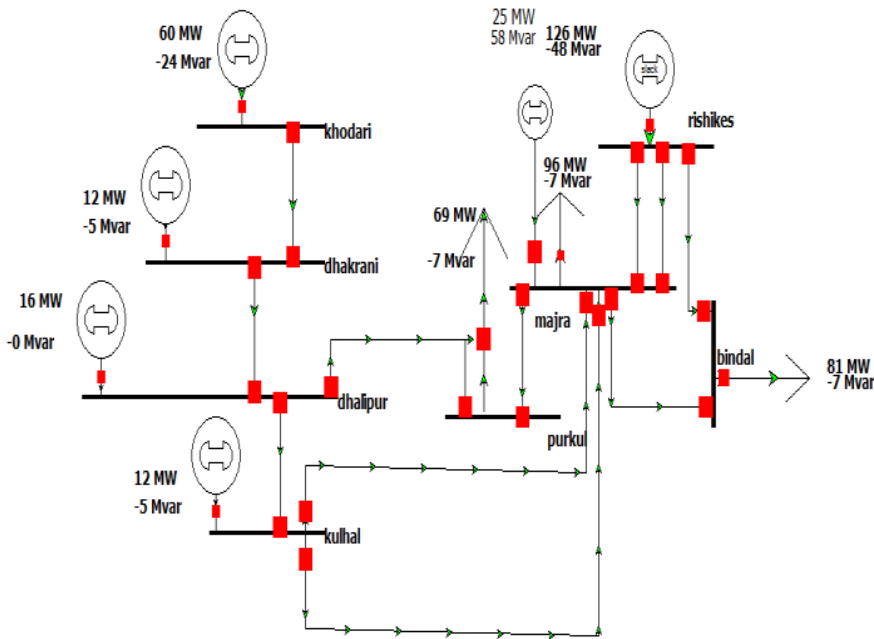

Fig.14 Dehradun system with one RES of 25MW at Majra bus

TABLE. 10 Ei OF THE SYSTEM WITH ONE RES

\begin{tabular}{|c|l|c|}
\hline From Bus & To Bus & E.I \\
\hline 4.0 & 6.0 & 51.0 \\
\hline 4.0 & 6.0 & 54.0 \\
\hline 5.0 & 6.0 & 59.8 \\
\hline 3.0 & 4.0 & 82.2 \\
\hline 6.0 & 7.0 & 82.4 \\
\hline 6.0 & 7.0 & 82.4 \\
\hline 6.0 & 8.0 & 82.4 \\
\hline 7.0 & 8.0 & 87.6 \\
\hline 3.0 & 5.0 & 92.4 \\
\hline 1.0 & 2.0 & 120.0 \\
\hline 2.0 & 3.0 & 143.4 \\
\hline
\end{tabular}

From table 10 above, the average $E_{i}$ of the system is $937.5835 / 11=85.23$. Hence, from the above two iterative cases it is concluded that with an additional RES at bus 6 the overall $\mathrm{E}_{\mathrm{i}}$ of the system improved and the overall system loading is enhanced.

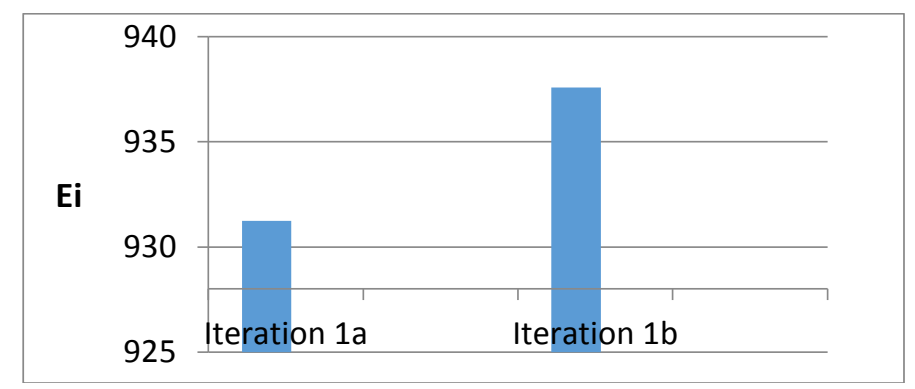

Fig.15 Graph for Economic Index with and without RES

Figure 15 above shows the increase in average $E_{i}$ of the system after applying analytical algorithm.

\section{CONCLUSION AND FUTURE SCOPE}

There are several approaches available for power system expansion planning with different available constraints. The approach given in this paper is based upon MW-Mile method comprises for deregulated power systems. The approach is simple and easy to implement for different configurations of power system e.g. load variations, generation variations, any available contingency in the system or other. Proposed methodology is applied to a practical power system which shows its ease of implementation and importance. Based on different scenarios, the given approach can be implemented in future on the following described areas.

1. The proposed methodologies in future can also be applied on GARVER's 6 bus, IEEE-9 and IEEE-30 etc. bus systems and also on practical systems to see the responses against various transmission system constraints.

2. The prescribed system can also be used as stand-alone system with storage system.

3 . The cost analysis of the system under consideration can also be done.

4. Transmission losses and their reduction could be part of the planning process. 
5. The load end can be used as input (predefined) in order to identify transmission plans. The consideration of transmission constraints in the generation planning process would be also a possible subject for future work.

6. In addition to this other software like ETAP, MATPOWER, etc. can also be used.

\section{REFERENCES}

[1] Junhua Zhao and John Foster, "Flexible Transmission Network Planning Considering the Impacts of Distributed Generation", Energy economics and managenent group, School of economics, Queensland university. Availableat: http://eemg.uq.edu.au/filething/get/194/01.pdf

[2] Xinsong Zhang, Yue Yuan, Boweng WU, Qiang Li, "A Novel Algorithm for Power System Planning Associated with Large-scale Wind Farms in Deregulated Environment" IEEE 4th International conference on electric utility deregulation and restructuring and power technologies (DRPT), 2011, China

[3] Kaur Raminder, Kaur Tarlochan, Kumar Maneesh, Verma Shilpa, "Optimal transmission expansion planning under deregulated environment: An analytical approach" IEEE 1st International Conf. on Power Electronics, Intelligent Control and EnergySystems (ICPEICES) 2016 India.

[4] Rajeev Kumar Gajbhiye,, Devang Naik, Sanjay Dambhare, and S. A. Soman, "An Expert System Approach for Multi-YearShort-Term Transmission System ExpansionPlanning: An Indian Experience" IEEE Trans. on Power Systems, VOL. 23, NO. 1, February 2008

[5] M. Oloomi, H. M. Shanechi, G. Balzer and M. Shahidehpour, "Transmission planning approaches in restructured power systems," in Proc. IEEE/Power Eng. Soc. Power Tech. Conf.,Bologna, Italy, vol.2, 2003.

[6] I. I. Skoteinos, G. A. Orfanos, P. S. Georgilakis and N. D.Hatziargyriou "Methodology for Assessing Transmission Investments in Deregulated Electricity Markets”, IEEE Trondheim PowerTech,2011

[7] Risheng Fang and David J. Hill, "A New Strategy for Transmission Expansion in Competitive Electricity Markets", IEEE Transactions on power systems, VOL. 18, NO. 1, February 2003

[8] V. S. K. Murthy Balijepalli, and S. A. Khaparde, "Novel Approaches for Transmission System Expansion Planning Including Coordination Issues" IEEE Power and Energy Society General Meeting, July 2010

[9] CEA General Guidelines for Substation, New Delhi, India, June 2012

[10] Manual on transmission planning criteria, New Delhi, India January 2013

[11] T. Tachikawa,Hiroyuki Kita, Hideharu Sugihara, Ken-ichi Nishiya and Jun Hasegawa "A study of transmission planning under a deregulated environment in in power system," in Proc. IEEE Int. Conf. Electric Utility Deregulation and Restructuring, pp. 649-654,2000

[12] Power transmission corporation of uttarakhand ltd. website available: www.ptcul.org

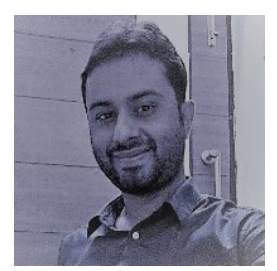

Maneesh Kumar (M'15-S'16) was born in Haridwar district of Uttarakhand state in Indian on Feb. 1987. He received his Bachelor degree in Electrical engineering from College of Technology, G.B. Pant University of Agriculture and Technology Pantnagar, Uttarakhand in 2009. He received his Master's degree in Electrical engineering from P.E.C University of Technology, Chandigarh, India in 2015 currently he is pursuing his $\mathrm{PhD}$. degree from Indian Institute of Technology, Roorkee, India, since Dec. 2015. He also worked as a lecturer for more than 3 years (from 2009 to 2013) and also assistant professor for 6 months (from July
2015 to Dec. 2015). His major research area includes power system. renewable energy systems, microgrids etc.

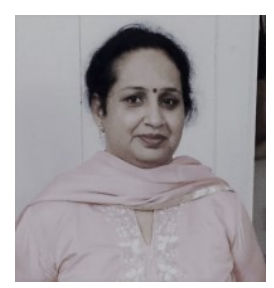

Raminder Kaur has received her Bachelor degree from P.E.C Chandigarh, India in 1984 and also her master's degree from the same institute in 1991. She has submitted her $\mathrm{PhD}$. thesis in 2017 and currently she is working as an assistant professor in P.E.C university of technology Chandigarh, India. She has more than 30 years of teaching experience. Her area of interest is power system planning, distributed generation, renewable energy systems etc. 